\title{
Viewing anti-immigrant hate online: An application of routine activity and Social Structure-Social Learning Theory
}

\author{
Matthew Costello, Salvatore J. Restifo, James Hawdon
}

Please cite this article as: Costello M., Restifo S.J. \& Hawdon J., Viewing anti-immigrant hate online: An application of routine activity and Social Structure-Social Learning Theory, Computers in Human Behavior (2021), doi: https://doi.org/10.1016/i.chb.2021.106927.

This is the version of the article that was submitted for publication. It is not the definitive version of record and will undergo additional copyediting, typesetting and review before it is published in its final form.

\footnotetext{
ABSTRACT

The increasingly prominent role of the Internet in the lives of Americans has resulted in more people coming into contact with various types of online content, including online hate material. One of the most common forms of online hate targets immigrants, seeking to position immigrants as threats to personal, national, economic, and cultural security. Given the recent rise in online hate targeting immigrants, this study examines factors that bring individuals into virtual contact with such material. Utilizing recently collected online survey data of American youth and young adults, we draw on insights from Routine Activity Theory and Social Structure-Social Learning Theory to understand exposure to anti-immigrant online hate material. Specifically, we consider how online routines, location in social structure, and social identity are associated with exposure. Results indicate that engaging in behaviors that can increase proximity to motivated offenders increases the likelihood of being exposed to anti-immigrant hate, as does engaging in online behaviors that bolster one's target suitability. Additionally, individuals who view Americanism as fundamental to their social identity are more apt to encounter anti-immigrant hate material on the Internet, as are those who are more dissatisfied with the current direction of the country.
} 
Keywords: Online Hate; Immigration; Routine Activities Theory; Social Structure-Social Learning Theory

\section{INTRODUCTION}

The Southern Poverty Law Center (SPLC) described 2016 as an "unprecedented year for hate" in the United States (Potok 2017). For the year, there were 6,121 reported hate crimes $^{1}$ (FBI 2017) and 917 active hate groups (SPLC 2019). But 2016 was not an anomaly. Reported hate crimes increased 17 percent (to 7,175 offenses) in 2017, and the number of active hate groups in the country reached a record 1,020 in 2018 (FBI 2018; SPLC 2019). Noticeably, immigrants, especially those from Latin America, the Middle East and Asia, are increasingly the targets of hate — both offline as well as online (FBI 2017; Kaleem, 2019; SPLC 2019). Indeed, in 2017, 60 percent of hate crimes targeted individuals because of their race/ethnicity/ancestry (FBI 2018), and between 2015 and 2017 the rate of exposure to online hate material attacking immigrants increased by more than 60 percent (Costello et al. 2019). The rapid growth of hate material targeting immigrants is alarming because aggressive and inflammatory online rhetoric and imagery can lead to intolerance and, in extreme instances, verbal and physical attacks against them (Stacey et al. 2011).

Given the surge in anti-immigrant hate material and the dangers it poses, it is crucial to identify and understand those factors that steer individuals toward such malicious online content. In this article,

\footnotetext{
${ }^{1}$ Estimates suggest U.S. hate crimes are severely underreported, averaging about 200,000 incidents annually from 2015-2017 (Bureau of Justice Statistics 2017).
} 
we examine dynamics associated with exposure to anti-immigrant hate material online using data on youth and young adult internet users. We begin with a brief description of online hate and contextualize its emergence and spread. We then turn to Routine Activity Theory (RAT) and Social Structure-Social Learning Theory (SSSL) and consider how these frameworks can help explain exposure to online hate. The former highlights the association between crime, offender, target and guardianship, while the latter calls attention to social learning processes embedded in group membership, culture, and structural environment. Next, we discuss anti-immigrant sentiment in the United States and how perceived national identity and satisfaction with the trajectory of the country can affect exposure to hate material targeting the foreign-born. This is followed by a description of our data $(\mathrm{N}=726)$, measures (attitudinal, demographic, situational), and analytic approach (logistic regression). We conclude with a discussion of our key findings, study limitations, and the broader implications and contributions of our work.

\section{Theory}

\subsection{Online Hate}

Online hate, also referred to as online extremism or cyberhate, is a type of cyberviolence that uses computer information technology to voice attitudes and opinions devaluing persons because of their race, ethnicity, immigrant status, religion, gender, sexual identity, and/or political persuasion - among other traits (Blazak 2009; Hawdon et al. 2017a). Online hate differs from other forms of cyberviolence, such as cyberstalking or cyberbullying, in that hate attacks target individuals based on their collective group membership (Costello et al. 2016a). While hate groups have long been attracted to the technological, geographic, and economic advantages the Internet affords (Meddaugh and Kay 2009), social media has accelerated the spread of online hate, offering individuals unassociated — or loosely associated — with hate groups easily accessible, user-friendly, and far-reaching platforms to publicize and communicate hate (Potok 2015). 
Cyberhate takes many forms and is spread by those on the political left and right, as well as white supremacists, eco-terrorists, and transnational jihadists (Brown 2009). Online hate, however, is presently monopolized by far-right extremists (Berger 2016; Potok 2015; Ratliff et al. 2015) who champion white supremacy and racial purity and stoke fear of impending white genocide. Immigrants, portrayed as a mounting threat not only to white ascendancy, but also white survival, are thus common targets of rightwing cyberhate. Websites dedicated to anti-immigrant hate regularly malign and marginalize the foreignborn through derogatory and dehumanizing characterizations (Gemignani and Hernandez-Albujar 2015), depicting them as a burden to taxpayers, labor market threat, and colonizing force producing social, moral, and cultural decay (Phadke et al. 2018). It should come as little surprise, then, that as the United States continues to diversify, projecting to reduce whites from a majority to a plurality by mid-century (Lieven 2016), anti-immigrant hate has become increasingly pervasive in cyberspace. In fact, survey data show that exposure to anti-immigrant hate online dramatically increased over the last few years (Costello et al. 2019). ${ }^{2}$

\subsubsection{Explaining Exposure to Anti-Immigrant Hate Online}

Recent scholarship has used a modified version of Cohen and Felson's (1979) Routine Activity Theory to examine cybercrime and victimization. Initially conceptualized to shed light on crime in a physical environment, RAT purports that crime is more likely when a motivated offender, suitable target, and inadequate guardianship converge in time and space. This framework, in turn, has been extended to explain various online abuses, including identity theft, harassment, fraud, and targeted hate (Bossler and Holt 2009; Pratt et al. 2010; Reyns 2013; Reyns and Henson 2015; Reyns et al. 2011).

RAT has similarly been used to explain exposure to general forms of online hate (Costello et al. 2016a), as well as online hate that specifically advocates violence (Hawdon et al. 2019). For instance,

\footnotetext{
${ }^{2}$ According to recent data, reported exposure to anti-immigrant hate online grew from 20.7 percent in 2015 to 32.6 percent in 2017—a jump of 63.5 percent (Costello et al. 2019).
} 
specific online behaviors, such as spending more time online (Costello et al. 2016; Keipi et al. 2017), avid social media use (Hawdon et al. 2019; Hawdon et al. 2014), and maintaining robust social networks (Hawdon et al. 2014) are found to increase the likelihood of encountering cyberhate. Moreover, engaging in antagonistic online behaviors (Hawdon et al. 2019), producing online hate material (Hawdon et al. 2014), and joining others in online deviance (Hawdon et al. 2019; Costello et al. 2016) can render individuals targets. Sexting, adding strangers to social media networks, and anonymously confiding in others online have also been identified as increasing targeting and cyber-victimization (Reyns et al. 2013; Reyns et al. 2016).

Capable guardianship, however, although shown to reduce criminal activity in a physical environment (Pratt and Cullen 2005), does not reliably reduce cyber-victimization (Bossler and Holt 2009; Leukfeldt and Yar 2016). This may reflect both the difficult task of operationalizing capable online guardianship, as well as challenges associated with policing a fundamentally anonymous, and theoretically limitless, online realm. Importantly, recent work shows that attempts among internet users to confront and self-regulate individuals engaging in hateful behavior can actually have the opposite of the intended effect. That is, attempts to challenge hate can increase an online user's visibility, which can lead to them becoming a target (Costello et al. 2017).

In sum, RAT offers important insights into cyber-victimization, including exposure to hate material. However, its application to this particular form of cyber-victimization faces a specific challenge; namely, RAT does not distinguish theoretically between wanted and unwanted exposure to online hate content. Because hate is in the eye of the beholder, and those advocating or agreeing with hateful ideology do not necessarily consider it nor mean it to be "victimizing" (Costello et al. 2016b), we argue that broader sociocultural conditions and context must be considered to fully capture and explain patterns of exposure to cyberhate. Thus, following others (Hawdon et al. 2019), we incorporate insights from Social Structure-Social Learning Theory (SSSL) into our analyses to complement RAT and offer an important corrective. 
SSSL explores how "variations in the social structure, culture, and locations of individuals and groups in the social system" (Akers 2009: xxviii) influence social learning processes that lead to criminal behavior. Specifically, SSSL highlights how differential social location (i.e., group membership), differential location in social structure (i.e., socio-demographic stratification), and differential social organization (i.e., structural environment) influence an individual's worldview. Like RAT, SSSL is typically used to explain crime that occurs in offline settings. Yet, these factors can influence an individual's online experiences as well, including their proximity to motivated offenders, visibility as a target of online deviance, and the likelihood of being under capable guardianship (Hawdon et al. 2019; Kaakinen et al. 2018). We therefore argue that the structural factors and social learning processes identified by SSSL influence victimization by molding those processes described by RAT.

In this study, we devote particular attention to the role of differential social location and differential location in social structure, as well as to what Akers (2009) refers to as theoretically defined variables - i.e., unspecified social structural factors that can affect learning processes that lead to criminality. Akers intentionally developed and described such variables broadly to allow for future development of SSSL. In this case, we explore belief systems that might affect the likelihood of being exposed to online hate targeting immigrants. Specifically, we consider whether individuals whose selfperception is defined by their status as an American and who are dissatisfied with the direction of the country are more likely to encounter anti-immigrant hate. The section that follows provides a backdrop to immigration, nativism, and American identity, and elaborates upon connections to cyberhate.

\subsubsection{Anti-Immigrant Sentiment in America}

The recent swell of anti-immigrant fervor in the U.S. fits a larger pattern and history marked by frequent moments and, at times, forceful waves of prejudice and hate. The nineteenth and early twentieth centuries — often looked back upon as exceptional eras in which millions of immigrants and immigrant families were incorporated into the American fabric - point to numerous instances when nativist fears gained public traction and expression through policy endorsing and, when successful, codifying 
segregationist and exclusionary practices (Bennett 1988; Lieberson 1980). Indeed, nativist claims that the foreign born — particularly those deemed nonwhite (including various European ethnics)—posed a serious cultural, criminal, economic, and political threat prompted such restrictionist federal policies as the Chinese Exclusion Act of 1882, the National Origins Act of 1924, and “Operation Wetback" in 1954 (Higham 1988; Ngai 2004).

The demographic character of the U.S. foreign-born population has of course changed dramatically over the past century, and Asian and European ethnics are no longer typical targets of antiimmigrant hostilities (Golash-Boza 2012; Timberlake and Williams 2012). Even so, disparaging stereotypes and prejudice against immigrants have in many respects remained constant. Nativist hyperbole past and present routinely centers on and equates the foreign born with violent crime, job competition, and politico-cultural insurgency (Restifo et al. 2019; Schrag 2010). Since the 1990s, such rhetoric has increasingly fixated upon unauthorized immigration from Latin America and the perceived terrorist threat of Arab and Muslim arrivals (Chavez 2013; Edgell et al. 2016). The presidencies of George W. Bush and Barack Obama in particular featured intensified immigration and national security policy enforcement relative to public and political pressure in these regards - though both administrations generally sought comprehensive immigration reform (Ilias et al. 2008; Obinna 2018).

Strikingly, the first decade and a half of the 2000s, particularly the period spanning the presidential administration of Barack Obama, witnessed a rapid rise in political partisanship on immigration issues as local Republican leadership increasingly aligned with and championed nativist views and action (Schain 2018; Williamson et al. 2011). The salience of this shift is reflected in the surge of local and state anti-immigration laws proposed and passed, including such blatantly hostile legislation as Arizona's SB 1070, Alabama's HB 56, and Georgia's HB 87. Nativist views gained further mainstream political purchase during the 2016 presidential election as Republican candidate and eventual president Donald Trump took advantage of growing public concerns over immigration by depicting the foreign born — especially those from Mexico and Muslim-majority countries—as dangerous criminals and terrorists (Bloch et al. 2020; Bonilla-Silva 2019; Potok 2017; see also Trump 2016). Moreover, once in 
office, Trump pursued an immediate and aggressive agenda targeting immigrants, including taking steps to construct a U.S.-Mexico border wall, implement a Muslim travel ban, and eliminate the Deferred Action for Childhood Arrivals (DACA) program. It should therefore come as little surprise that immigration is now viewed by the broader American public as a top concern confronting the nation (Jones 2019). Indeed, Gallup data from July 2019 shows that 27 percent of Americans view immigration as the most important problem — surpassing all other issues for the polling period and representing a record for immigration in Gallup polls.

The growing concern over immigration in the U.S. coincides with, and is likely linked to, resurgent nationalist attitudes (Brands 2017). Marshalling this revival, President Trump loudly and unabashedly embraced nationalism, exclaiming at a rally in 2108, "You know what I am? I'm a nationalist, O.K. I'm a nationalist. Nationalist! Use that word! Use that word!" A day later in the Oval Office, Trump reiterated his affinity for the title, stating “I am a nationalist. It's a word that hasn't been used too much. Some people use it, but I'm very proud. I think it should be brought back" (Baker 2018).

Fundamentally, a nationalist ethos frames patriotism as an emotion, akin to love of one's family, with citizens of a nation bound by a shared past, common culture, and collective morality (Mead 2013). As such, nationalism is expressly about social identity and a feeling of belonging to something bigger than the individual (Hogg and Abrams 1988). Social identity theory, in turn, emphasizes the salience of group memberships to one's sense of self and denotes how identity construction involves comparing oneself to others. Those deemed similar are recognized as in-group members, while those deemed distinct — across key status dimensions — are viewed as out-group members (Steets and Burke 2000). In pursuit of a positive sense of self, individuals draw favorable comparisons between their in-group and other out-groups, effectively highlighting the distinctiveness — and often alleged superiority — of one's social identity (Grant and Brown 1995). This sense of distinction can translate into evaluative bias (Branscombe et al. 1993; Sidanius et al. 1994), devaluing out-groups (Branscombe and Wann 1994), and even discrimination (Cagnon and Bourhis 1996) when in-group identification is particularly robust or finite resources are at stake (Oakes et al. 1994; Tajfel 1978; Hawdon 2014). 
The immigration debate in the U.S. is routinely couched in nationalistic terms, emphasizing the role of social identity. Members of the in-group nation, or us, are pitted against them, the would-be social, cultural, ideological, linguistic, and economic interlopers from abroad (Hollinger 2006) who carry the potential to upend the delicate balance between national unity and diversity (Citrin and Wright 2009). Long-standing concerns over the ability and willingness of immigrants, especially immigrants who are most dissimilar from the native population, to assimilate to American ideals buoy fears of an erosion of national identity (Higham 1988; Schrag 2010). Indeed, multiculturalism is commonly framed as a direct threat to Americanism (Citrin and Sides 2008; Citrin and Sears 2009).

Since identification as American - like all identities - is only meaningful vis-à-vis some other, and because status is inexpansible (Hawdon 2014; Milner 2013), promoting one's identity as American can come at the cost of the identities of others, including immigrants. Extant work demonstrates that perceived threat to social identities increase ethnocentrism (Bourhis and Giles 1977; Grant 1993; see also Bloch et al. 2020; Chavez 2013), and we therefore expect individuals who view their status as American as core to their identity to be more apt to seek out and/or notice materials that enhance the status of their identity—specifically, cyberhate targeting immigrants. Similarly, while the U.S. population is increasingly diversifying (Lieven 2016), concerns over immigration are accelerating (Jones 2019). Given the growing belief that immigration is a major problem in need of immediate correction, coupled with the long history of scapegoating the foreign-born for national problems, including crime, unemployment, wage depression, and social and cultural decay (Pollin 2011; Rothschild et al. 2013; Schain 2018), we anticipate that individuals who are dissatisfied with the country's current trajectory will be more likely to encounter and/or view anti-immigrant cyberhate.

\section{MATERIALS AND METHODS}

The analytic sample for this study consists of 726 internet users age 15 to 36 who were exposed to online hate. Consistent with prior research, we focus on youth and young adults because they are particularly active on social media and thus more likely to encounter online hate material (e.g. Costello et 
al. 2016a; Räsänen et al. 2016). Data were collected by Survey Sample International (SSI) in December 2017 from demographically balanced panels. SSI recruited participants through random digit dialling and other permission-based techniques. Potential respondents were sent email invitations, and SSI provided several incentives to participants to take the surveys. Importantly, SSI stratified the sample to reflect the U.S. population on key demographic traits. Women were nonetheless disproportionately represented in the sample (66\%), so we constructed weights based on the percentage of women in the U.S. age 15 to 36. All results reported herein are based on the weighted data. Notably, demographically balanced online panel data such as these are typical for investigating hate material on the Internet (see, e.g., Costello et al. 2016a,b; Näsi et. al. 2014; Näsi et. al. 2015).

\subsection{Dependent Variable}

Our analyses center on exposure to anti-immigrant hate online. This outcome is measured dichotomously, with 1 indicating respondents encountered anti-immigrant hate material online within three months just prior to taking the survey and 0 indicating they did not. Respondents were first asked if they had seen or heard any material online that expressed negative views about any group because of their race, nationality, ethnicity, sexual orientation, gender, political views, immigrant status, or religion in the past three months. Those who responded affirmatively where then asked what the hate they saw targeted, and respondents were provided a list of choices including race or ethnicity, sexual orientation, political views, religious conviction or beliefs, gender or gender identity, etc. Over one-third of study participants reported encountering hate online that targeted "nationality or immigrant status" during the preceding three months, making it one of the most common forms of cyberhate seen. Table 1 offers a breakdown of the type of online hate to which respondents were recently exposed.

\begin{tabular}{cc}
\hline \hline Saw Online Hate in the Past 3 Months & Percent \\
Yes & 68.5 \\
No & 31.5 \\
\hline Online Hate Pertained to: & Percent of those Exposed $^{\mathbf{1}}$ \\
\hline Race & 51.6 \\
Sexual Orientation & 36.4
\end{tabular}


Immigrant Status/Nationality

35.4

Politics

33.2

Religion

25.5

Gender Identity

22.4

Gender

Appearance

13.8

Disability

6.5

Other

0.3

$\overline{{ }^{1} \text { Respondents could select multiple categories, so percentages do not add to } 100 \%}$

Table 1. Exposure to Online Hate Material by Type of Hate

\subsubsection{Independent Variables}

We begin with Routine Activity Theory and consider its key dimensions (i.e., proximity to motivated offenders, target suitability, and guardianship) relative to online experiences. Recent work demonstrates that certain online behaviors can bring online users into virtual proximity to hateful materials, as well as render them suitable targets for cyberviolence (Costello et al. 2016a,b; Hawdon et al. 2017b). First, we take into account several activities that tap into proximity to motivated offenders, or, more specifically, "dangerous" virtual spaces that might contain anti-immigrant hate. These activities include the amount of time respondents spend online and the number of social networking sites (SNS) they use. Time online is measured by asking respondents approximately how many hours per day they spend using the Internet. Possible responses range from 1 ("less than one hour per day)" to 6 ("ten or more hours per day"). SNS usage is gauged by asking respondents to identify any popular social networking mediums (e.g., Facebook, Twitter, YouTube) they used during the preceding three months. These measures are dichotomous, coded 1 for use of a given site and 0 otherwise. We anticipate that spending more time online and greater SNS usage will increase online users' virtual proximity to motivated offenders, and thus make exposure to anti-immigrant hate more likely.

Next, we assess target suitability. Here, we control for expressing political views online, being directly targeted by online hate, and immigrant status. Although we are examining exposure to hate, not targeting, it is likely that many of the same factors that make respondents targets will also place them in virtual proximity with it. Respondents were asked if they voiced political views online within the past 
year. Responses were coded 1 for such activity and 0 otherwise. Political views can be contentious, and their expression can be seen as antagonistic, heightening a person's target suitability (Hawdon et al. 2019). We thus expect the expression of political views online to correlate with exposure to antiimmigrant hate. Respondents were also asked if they have ever been the direct target of online hate. Responses were coded 1 if so and 0 otherwise. Being targeted can indicate an individual occupies hostile online spaces where hate exists (Costello et al. 2016b). Indeed, repeat victimization is common (Fagan and Mazerolle, 2011; Finkelhor et al. 2007), and individuals who experience one type of cybervictimization are more likely to be confronted by other types (Reyns et al. 2013). As such, we expect that persons that have previously been the target of hate will be more likely to be exposed to anti-immigrant hate. Immigrant status is coded 1 if persons were born outside the U.S. and 0 otherwise. Since immigrants are often direct targets of anti-immigrant hate online, we anticipate that they will be at greater risk to encounter such material.

Finally, we assess guardianship. We use respondents' living arrangement as a proxy, in this instance, to capture online guardianship. This is consistent with prior work on guardianship in online contexts (e.g., Räsänen et al. 2016; Reyns et al. 2016). This measure is dichotomous, coded 1 if respondents live alone and 0 if not. Living alone represents a low level of guardianship (Reyns et al. 2016), and potentially an increased likelihood for engaging in online deviance. We therefore expect living alone to correlate with exposure to anti-immigrant cyberhate.

Building on Routine Activity Theory, we blend insights from Social Structure-Social Learning Theory to further develop and extend our understanding of cyber-victimization. As suggested by SSSL, individuals' online behaviors are shaped by, if not largely a result of, social learning processes. As such, we introduce several measures approximating core tenets of SSSL. These include differential location in social structure, differential social location, and two theoretically defined variables.

We take into account differential location in social structure using a series of socio-demographic indicators. SSSL argues that location in social structure impacts social learning processes that may lead to 
criminal behavior (Akers 2009). Taken a step further, prior research suggests that those most attracted to the current brand of rightwing hate, including anti-immigrant hate, are white, relatively uneducated men who are economically marginalized and politically conservative (see, e.g., Baysinger 2006; Berlet and Lyons 2018; Global Post 2015). We therefore introduce measures for race/ethnicity, gender, education, economic engagement, and political ideology. Race/ethnicity is dichotomous, coded 1 if respondents identified as white and 0 nonwhite. Gender is coded 1 if respondents identified as male and 0 female. Education is measured as the highest degree earned, ranging from 1 ("less than a high school diploma") to 5 ("a master's degree or professional degree"). Economic engagement is dichotomous, coded 1 if individuals are in school or working full-time and 0 if unemployed or working part-time. Political ideology is based on a 7-point scale, ranging from 1 ("extremely liberal") to 7 ("extremely conservative"). As a precaution, we also control for age in years.

Next, we measure differential social location (or membership in various social groups). This is done by gauging respondents' closeness to primary groups and any online communities to which they belong. Closeness to primary groups takes the average of two measures, closeness to family and closeness to friends. Both are based on a 5-point scale, ranging from 1 ("not at all close") to 5 ("very close"). Closeness to online communities uses this same 5-point scale. We expect that embeddedness in such social networks will reduce the likelihood of encountering anti-immigrant hate material online because poor social integration and a lack of social bonds has been linked to risky behavior (Colvin et al. 2002), which could include viewing cyberhate.

Finally, we introduce two theoretically-defined variables—as described by SSSL (Akers 2009). The first is a three-factor composite measure that approximates respondents' self-perceived Americanism. This is based on responses to the questions: 1) "How much is being American an important part of how you see yourself?" 2) "How proud are you to be an American?" and 3) "How much do you think your friends see you as American?" Each question is scored on an identical scale, ranging from 0 ("Not at all") to 10 ("Completely"). Responses to the questions are highly correlated and have a Cronbach's Alpha of 
.851 (indicating a high degree of shared variance). We expect persons that define themselves by a strong sense of Americanism will be more likely to encounter anti-immigrant hate online. Our second measure is based on responses to the question: "How satisfied are you with the way things are going in the United States right now?" We reverse-coded the original scale so 1 represents "completely satisfied" and 7 represents "completely dissatisfied." We anticipate that those who are dissatisfied with the current direction of the country will be more likely to come across anti-immigrant hate content.

Table 2 reports means, standard deviations, and minimum and maximum values for all variables. Bivariate correlations (available upon request) suggest multicollinearity is not an issue. Moreover, the mean variance inflation factor for the complete set of covariates (1.26) indicates multicollinearity is not a statistical problem.

\begin{tabular}{|c|c|c|c|c|}
\hline Variable & Mean/\% & Std. Dev. & Min. Value & Max. Value \\
\hline Anti-Immigrant Hate & 0.35 & 0.48 & 0 & 1 \\
\hline \multicolumn{5}{|l|}{ Proximity to Offenders } \\
\hline Time Online & 3.59 & 1.31 & 1 & 6 \\
\hline Use Facebook & 0.90 & 0.30 & 0 & 1 \\
\hline Use Twitter & 0.41 & 0.49 & 0 & 1 \\
\hline Use YouTube & 0.87 & 0.34 & 0 & 1 \\
\hline Use Instagram & 0.60 & 0.49 & 0 & 1 \\
\hline Use Snapchat & 0.52 & 0.50 & 0 & 1 \\
\hline Use 4 chan/8chan & 0.02 & 0.14 & 0 & 1 \\
\hline Use Reddit & 0.19 & 0.39 & 0 & 1 \\
\hline \multicolumn{5}{|c|}{ Target Suitability \& Guardianship } \\
\hline Voice Political Views Online & 0.43 & 0.50 & 0 & 1 \\
\hline Previously Targeted by Hate & 0.27 & 0.44 & 0 & 1 \\
\hline Immigrant & 0.05 & 0.21 & 0 & 1 \\
\hline Live Alone & 0.11 & 0.31 & 0 & 1 \\
\hline \multicolumn{5}{|l|}{ Structural \& Social Location } \\
\hline White & 0.80 & 0.40 & 0 & 1 \\
\hline Male & 0.51 & 0.50 & 0 & 1 \\
\hline Education & 2.68 & 1.28 & 1 & 5 \\
\hline Political Ideology & 4.00 & 1.60 & 1 & 7 \\
\hline Economic Engagement & 0.70 & 0.46 & 0 & 1 \\
\hline Age & 24.49 & 6.47 & 15 & 36 \\
\hline Closeness to Primary Group & 4.15 & 0.88 & 1 & 5 \\
\hline
\end{tabular}


Closeness to Online Community

Theoretically Defined Variables

American Identity

Dissatisfied with Direction of US
2.84

0.02

4.81
1.23

0.98

1.63
1

$-2.53$

1
5

1.42

7

\section{Table 2. Descriptive Statistics for Dependent and Independent Variables}

\subsubsection{Analytic Strategy}

We utilize logistic regression to examine exposure to anti-immigrant online hate because our dependent variable is dichotomous in nature (i.e., respondents reported seeing online hate targeting immigrants $o r$ they did not). The effects of independent variables are reported as odds ratios, which are more intuitively interpretable than coefficients. Odds ratios show relative changes in the odds of an outcome when an independent variable's value is increased by one unit, holding all other effects constant. We use a three-model sequence for our analyses. Model 1 controls for core aspects of RAT (i.e., proximity to motivated offenders, target suitability, and guardianship). Models 2 and 3, in turn, assess key dimensions of SSSL. Model 2 incorporates measures approximating differential location in social structure and differential social location, while Model 3 introduces our two theoretically-defined variables.

\section{RESULTS}

Table 3 reports odds ratios from logistic regression models predicting exposure to anti-immigrant online hate. Model 1 centers on RAT and offers mixed support. First, Facebook, YouTube, Reddit, and Snapchat use are associated with greater odds of exposure to anti-immigrant cyberhate (Odds Ratios $=$ $2.08 ; \mathrm{p}<.05,1.59 ; \mathrm{p}<.05$, and $1.63 ; \mathrm{p}<.05$, respectively). This suggests participation in these specific social networking mediums brings online users into virtual proximity with motivated offenders. Time spent online and other social networking sites, however, are not significant. Next, we find that those voicing political views online are more than twice as likely to encounter anti-immigrant online hate (Odds Ratio $=2.20 ; \mathrm{p}<.001)$. This dovetails with notions of target suitability and suggests political expression may place online users at greater risk of being targeted. We also find evidence that points to the salience 
of immigrant status, but in this instance, our estimates run counter to expectations. That is, immigrants, the assumed target of anti-immigrant hate, are less likely to encounter such content online than their U.S.born counterparts $($ Odds Ratio $=0.51 ; \mathrm{p}<.05)$ — perhaps signaling that U.S.-born Americans are not necessarily targeted as victims, but rather as a potentially captive audience for anti-immigrant online hate. Finally, neither previously being targeted by cyberhate nor living alone-which tap into target suitability and guardianship, respectively_are significant predictors of viewing anti-immigrant hate.

Model 2 incorporates measures approximating key aspects of SSSL. Socio-demographic characteristics account for differential location in social structure, while closeness to primary groups and online communities capture differential social location. Noticeably, YouTube, Reddit, and Snapchat use are no longer significant. Moreover, we find little, if any, evidence in support of these aspects of SSSL. Regarding location in social structure, most socio-demographic measures in this model are not significantly associated with exposure to anti-immigrant online hate. The one exception is political ideology. But in this instance our estimates are inconsistent with prior research and expectations. Specifically, more politically conservative individuals are less likely to encounter anti-immigrant online hate than more politically liberal individuals (Odds Ratio $=0.82 ; \mathrm{p}<.001)$. With regards to social location, we similarly find conflicting evidence. Here, closeness to primary groups is associated with greater odds of exposure to anti-immigrant cyberhate (Odds Ratio $=1.24 ; \mathrm{p}<.05)$. This suggests close ties to family and friends may in fact point persons toward anti-immigrant online hate material— given shared attitudes and values - rather than shield them from it as initially anticipated. Closeness to online communities, however, although in the expected direction, is not statistically significant.

Model 3 introduces our theoretically-defined variables and offers support for predictions. Results denote that persons that define themselves by a strong American identity are more likely to view antiimmigrant online hate (Odds Ratio $=1.19 ; \mathrm{p}<.05)$. By the same token, the more dissatisfied individuals are with the current direction of the country, the more likely they are to encounter anti-immigrant content $($ Odds Ratio $=1.32 ; \mathrm{p}<.001)$. These findings call important attention to the link between nationalist leanings and hate found in online spaces. Relatedly, the effect of immigrant status is diminished and no 
longer statistically significant. This suggests American identity and concerns play a more direct role which relegates nativity to secondary relevance.

Model 3 also points to a potentially unique dynamic between location in the social structure and nationalist leanings in that economic engagement is now significant (but only once we include these latter measures) such that those who are economically engaged are substantially less likely to view antiimmigrant hate $($ Odds Ratio $=0.68 ; \mathrm{p}<.05)$, as expected. The significance of economic engagement suggests the existence of a suppression effect. A suppressor variable increases the predictive validity of another variable by its inclusion in a regression equation (Tzelgov \& Henik 1991). Put differently, suppression is present when the size of a relationship between an independent variable and the dependent variable increases when a third variable is introduced (MacKinnon, Krull \& Lockwood 2000). To explore this further, we entered the two theoretically-defined variables in Model 3 into the regression equation separately, finding that economic engagement was suppressed by dissatisfaction with the direction of the U.S. since its inclusion resulted in the significant effect of economic engagement. ${ }^{3}$ The magnitude of the difference in the odds ratio between persons that are economically engaged and those that are not increases by .06 once dissatisfaction with the direction of the country is included, such that persons that are economically engaged now have significantly lower odds of encountering anti-immigrant online hate than those that are not. ${ }^{4}$

\footnotetext{
${ }^{3}$ To confirm the existence of a suppression effect, we explored correlations between the main effect, likely suppressor variable, and dependent variable (McClendon 2002). The absolute value of the correlations between one of the independent variables, economic engagement, and the dependent variable, exposure to anti-immigrant online hate, is less than the absolute value of the product of the other two correlations - between dissatisfaction with the direction of the country and exposure to anti-immigrant online hate and between dissatisfaction and economic engagement -indicating the existence of a suppression effect.

${ }^{4}$ As a precaution, we estimated the magnitude of the difference in the odds ratio for economic engagement taking into account dissatisfaction with the direction of the country both with and without American identity. Our estimates for economic engagement were essentially identical in both models, further bolstering confidence that dissatisfaction with the direction of the country is the factor driving the suppression effect.
} 


\begin{tabular}{|c|c|c|c|c|c|c|}
\hline \multirow[b]{2}{*}{ Proximity to Offenders } & \multicolumn{2}{|c|}{ Model 1} & \multicolumn{2}{|c|}{ Model 2} & \multicolumn{2}{|c|}{ Model 3} \\
\hline & O.R. & Std. Error & O.R. & Std. Error & O.R. & Std. Error \\
\hline Time Online & 1.08 & 0.07 & 1.08 & 0.07 & 1.06 & 0.07 \\
\hline Use Facebook & $2.08^{*}$ & 0.75 & $1.20 *$ & 0.74 & $1.98 *$ & 0.73 \\
\hline Use Twitter & 0.95 & 0.18 & 0.90 & 0.18 & 0.91 & 0.18 \\
\hline Use YouTube & $1.63 *$ & 0.46 & 1.58 & 0.46 & 1.60 & 0.47 \\
\hline Use Instagram & 0.93 & 0.20 & 0.90 & 0.19 & 0.94 & 0.20 \\
\hline Use Snapchat & $1.39 *$ & 0.27 & 1.39 & 0.29 & 1.37 & 0.29 \\
\hline Use 4chan/8chan & 2.00 & 1.45 & 2.96 & 2.61 & 3.31 & 3.02 \\
\hline Use Reddit & $1.59 *$ & 0.36 & 1.47 & 0.36 & 1.41 & 0.36 \\
\hline \multicolumn{7}{|l|}{ Target Suitability \& Guardianship } \\
\hline Voice Political Views Online & $2.20 * * *$ & 0.39 & $2.14 * * *$ & 0.39 & $2.07 * * *$ & 0.38 \\
\hline Previously Targeted by Hate & 1.17 & 0.22 & 1.22 & 0.25 & 1.24 & 0.26 \\
\hline Immigrant & $0.51 *$ & 0.19 & $0.51 *$ & 0.19 & 0.60 & 0.22 \\
\hline Live Alone & 1.14 & 0.31 & 1.22 & 0.36 & 1.35 & 0.42 \\
\hline \multicolumn{7}{|l|}{ Structural \& Social Location } \\
\hline White & ---- & ----- & 1.07 & 0.24 & 1.03 & 0.24 \\
\hline Male & ----- & ----- & 0.96 & 0.18 & 1.04 & 0.20 \\
\hline Education & ----- & ---- & 1.10 & 0.10 & 1.12 & 0.11 \\
\hline Political Ideology & ----- & ----- & $0.82 * * *$ & 0.05 & $0.87 *$ & 0.05 \\
\hline Economic Engagement & ----- & ----- & 0.74 & 0.15 & $0.68 *$ & 0.14 \\
\hline Age & ---- & ----- & 0.98 & 0.02 & 0.98 & 0.02 \\
\hline $\begin{array}{l}\text { Closeness to Primary Group } \\
\text { Closeness to Online }\end{array}$ & ---- & ---- & $1.24 *$ & 0.13 & $1.23 *$ & 0.14 \\
\hline Community & ----- & ----- & 0.91 & 0.07 & 0.95 & 0.07 \\
\hline \multicolumn{7}{|l|}{ Theoretically Defined Variables } \\
\hline $\begin{array}{l}\text { American Identity } \\
\text { Dissatisfied with Direction of }\end{array}$ & ----- & ----- & ----- & ----- & $1.19^{*}$ & 0.12 \\
\hline US & ----- & ----- & ----- & ----- & $1.32 * * *$ & 0.09 \\
\hline $\mathrm{N}$ & \multicolumn{2}{|c|}{726} & \multicolumn{2}{|c|}{726} & \multicolumn{2}{|c|}{726} \\
\hline Wald X2 & \multicolumn{2}{|c|}{52.41} & \multicolumn{2}{|c|}{66.78} & \multicolumn{2}{|c|}{81.39} \\
\hline Log Pseudolikelihood & \multicolumn{2}{|c|}{-441.97} & \multicolumn{2}{|c|}{-429.87} & \multicolumn{2}{|c|}{-418.73} \\
\hline
\end{tabular}

${ }^{*} \mathrm{p}<.05,{ }^{* *} \mathrm{p}<.01, * * * \mathrm{p}<.001$ (two-tailed tests)

Table 3. Logistic Regression Analysis of Exposure to Anti-Immigrant Hate Material Online 


\section{DISCUSSION}

At various points in U.S. history, anti-immigrant hate and fear has captured the American imagination and gained broad public and political support. The twenty-first century, particularly since the 2016 election of President Donald Trump, has witnessed a surge in such views as well as their rapid spread via the Internet. Given this troubling reality, we draw on a sample of internet users to assess how online behaviors, guardianship, differential location in social structure, differential social location, national identity, and views on the state of the nation relate to exposure to anti-immigrant hate material. Blending insights from Routine Activity Theory and Social Structure-Social Learning Theory—two perspectives generally applied to crime and victimization in offline environments - we expand on prior research and offer several important takeaways.

First, we consider core aspects of RAT (i.e., proximity to motivated offenders, target suitability, and guardianship) to shed light on dynamics associated with seeing anti-immigrant hate online. In general, we find only modest support. Time spent online and social networking site usage, which tap into proximity to motivated offenders, show mixed results. Specifically, time spent online does not have a significant effect, while use of certain popular networking sites increases contact with anti-immigrant content. But only Facebook use consistently correlates with seeing anti-immigrant cyberhate. This could be the result of Facebook's expansive network. Boasting over two billion monthly active users, Facebook remains the most-used social networking site (Hutchinson 2019). Alternatively, this could suggest that other major sites are more effectively policing their platforms for cyberhate. Taken together, these findings suggest it is not simply a matter of being online, but rather, virtual contact and engagement with others on specific online platforms factor in.

We similarly find mixed support with respect to target suitability and related online behaviors, including discussing politics and being targeted by cyberhate, as well as immigrant status. In this instance, previously being the target of hate is not associated with seeing anti-immigrant material online. In contrast, voicing political views online increases exposure to anti-immigrant material. This makes sense given the partisanship and contentiousness surrounding immigration and related debates. Indeed, 
persons that are politically active online may search for such content to engage others and "battle it out." We also do not find evidence to suggest immigrants, the assumed target of anti-immigrant online hate, are at greater risk of exposure to it than the U.S.-born. Instead, results show the U.S.-born are more likely to encounter such content. This likely speaks to the importance of immigration to Americans, the extent to which the topic dominates mainstream U.S. media and politics, and the fact that those seeking more information may eventually find anti-immigrant hate material by accident or by choice.

Our analyses thus offer some support for the application of RAT — relative to proximity to motivated offenders and target suitability — to online environments and signal its potential value for explaining contact with anti-immigrant hate. Noticeably though, living alone, which we use to assess guardianship, is not significant in our models. This is consistent with several prior works in this vein that find guardianship — both offline and online — to be generally ineffective at curtailing various online activities (see, e.g., Costello et al. 2016a; Bossler and Holt 2009; Leukfeldt and Yar 2016). Still, our consideration of online habits, routines, and experiences is only one part of a nuanced and complex set of dynamics.

To complement and extend upon the insights offered by RAT, we incorporate and explore elements of SSSL (i.e., location in social structure, social location, and theoretically defined variables). We turn first to socio-demographic characteristics, teasing out linkages between location in social structure and exposure to anti-immigrant hate. Although we find limited evidence of the centrality of such factors within online spaces, political ideology and economic engagement stand out. Political ideology estimates, in this instance, show that more conservative persons are less likely to encounter antiimmigrant hate material than more liberal persons. This contrasts with initial expectations and may otherwise point to a more general targeting of liberals for hate in online spaces. Economic engagement, in turn, does not have a significant effect on viewing anti-immigrant hate unless we control for dissatisfaction with the direction of the country, indicating a suppression effect. That is, the effect of work/school status on exposure is enhanced and simultaneously clarified by taking into account views on the current trajectory of the U.S. Specifically, the correlation between economic engagement and 
exposure to anti-immigrant hate among those who express dissatisfaction with the nation is approximately twice that of the correlation among those who are satisfied. As such, unless satisfaction with the direction of the country is controlled for, the relationship between economic engagement and exposure to hate is suppressed. This might suggest that much of the dissatisfaction with the current direction of the country expressed by some study participants is tied to perceived labor market threats, especially from immigrants (see Restifo et al. 2019; Wallace and Figueroa 2012).

Our analyses go further still and we explore how differential social location might shape exposure to anti-immigrant online hate. We focus here on closeness to primary groups and online communities. Although it is often assumed — and we expected — that persons with strong ties to family, friends, and even online groups, will be more receptive to and share mainstream attitudes and values, and thus be less likely to encounter anti-immigrant online hate, our analyses suggest otherwise. Namely, we find that persons that are closer to primary groups are more likely to be exposed to anti-immigrant cyberhate. This suggests it is not necessarily socially isolated individuals or loners that feel rejected and seek out such content, but instead persons with family and friends that may be sympathetic to and even advance antiimmigrant views. We do not find evidence to suggest those that are particularly isolated from or connected to online communities are at greater risk.

Importantly, within the framework of SSSL (Ackers 2009), we develop and introduce two theoretically defined variables into our analyses to capture and evaluate a belief system that might affect exposure to anti-immigrant hate online — a belief system embedded within and reflective of the broader U.S. socio-cultural and structural context. Focusing on the importance of American identity and beliefs about the trajectory of the country, our results denote the impact of a nationalist ideology and call attention to the potency of resurgent nationalist rhetoric in mainstream politics. Indeed, the current U.S. politico-cultural climate has bolstered and spread an unmistakable us versus them mindset, pitting "real" Americans against a supposed unfamiliar other. Taken together, the theoretical synthesis and analyses we offer highlight the convergence of certain online activities (i.e., SNS usage and voicing political views), 
socio-demographic characteristics (i.e., nativity, political ideology, and economic engagement), and a nationalist worldview for coming into contact with anti-immigrant hate online.

\section{STUDY LIMITATIONS}

This study offers important insights into factors associated with encountering anti-immigrant cyberhate. Nevertheless, there are several data limitations worth mentioning. For instance, because we use panel data, we cannot be certain that the online survey respondents included in our analyses do not differ in potentially meaningful ways from those who declined to participate. Even so, such data are valuable for advancing our understanding of online behavior and experiences, as well as prejudice and inequality (see, e.g., Costello et al. 2019; Hawdon et al. 2019). Another possible limitation stems from our decision to restrict our sample to individuals age 15 to 36 . We did so because not only are youth and young adults avid internet users, they are also more likely than other age demographics to encounter hate material online. This limits the generalizability of our findings, however, and it is also possible individuals outside this age group might be more or less likely to specifically encounter anti-immigrant online hate. Relatedly, we rely on survey participants to determine what constitutes hate and hateful online content. While we offered respondents a broad definition of online hate before they began the survey, it is probable that some individuals interpreted similar terms, issues, and images differently. Thus, what one person designates as hate, another might not.

A final caveat to our study is our limited operationalization of capable guardianship - a central feature of RAT. We used a measure of offline guardianship, whether an individual lives alone or not, because living alone could serve as a general measure of behavioral guardianship. As noted earlier, although capable guardianship is the most widely tested and supported dimension of RAT in offline settings (see Pratt \& Cullen, 2005), its adaptation to online contexts has produced inconsistent findings (e.g., Bossler \& Holt, 2009; Choi, 2008; Costello et al. 2016a, b 2016; Leukfeldt \& Yar, 2016; Reyns, 
2015). This is in part due to the difficulty in conceptualizing online guardianship (Vakhitova, Reynald, \& Townsley, 2016). For instance, some researchers have operationalized online guardianship as target hardening or physical guardianship, using measures such as the use of firewalls, antivirus programs, filtering, and blocking software (Bosler and Holt 2009; Fleming et al. 2006). Others have used peer deviance as a measure of lack of guardianship because deviant peers should be less likely to act in line with online guardianship (Bossler et al. 2012; Bossler and Holt 2009; Reyns, Henson, and Fisher 2016). Still others have taken an approach akin to ours, measuring guardianship based on respondents' living arrangements (e.g., Costello et al. 2016a,b; Räsänen et al. 2016; Reyns et al. 2016). These approaches, however, have failed to capture or suggest a consistent effect of guardianship on online victimization, and this may well be due to a lack of quality measures. As such, we encourage future research to explore improved measures and new dimensions of potential online guardianship.

\section{CONCLUDING REMARKS}

The discourse on immigration in America has become particularly acrimonious over the past several years. The racial/ethnic diversification of the U.S population has roiled nationalist fervor and reignited debate over what it means to be an American and who has the right to claim American identity. The 2016 election of President Trump, and the nationalist insurgency that swept Trump into office, portends to reverse decades of U.S. foreign policy, foregoing global integration and a global leadership role for isolationism. Today, renowned scholar Francis Fukuyama's proclamation that the end of the Cold War signaled the triumph of Western-style liberal democracy in the battle of ideologies, and thus the end of history, seems premature (Fukuyama 1992). Indeed, the United States and parts of Western Europe, long-standing bastions of liberal democracy, have recently witnessed neo-nationalist insurgencies seeking a tiered system (Mammone 2019) incongruent with a fundamental precept of liberal democracy - equal citizenship. 
The rise in anti-immigrant (and pro-nationalistic) sentiment in America carries alarming risks. As anti-immigrant hate material is spreading online (Costello et al. 2019), so too is violence targeting immigrants (SPLC 2019; FBI 2017). Given what we know about the effect of exposure to online content on offline behavior, these concurrent trends are intertwined (FBI 2011; Leets 2002; see also Freilich et al. 2011; The New America Foundation International Security Program 2015). It is thus not only necessary, but critical to develop a deeper understanding of those factors that bring online users into virtual contact with cyberhate targeting immigrants. Importantly, we find that certain attitudes concerning social identity affect the likelihood of doing so, and by blending Routine Activity Theory and Social Structure-Social Learning Theory, we suspect that these same belief systems partially pattern online behaviors that also increase the prospect of exposure to anti-immigrant online hate. We encourage researchers to explore this topic further, potentially uncovering ways to help online users avoid various forms of cyberhate, or at least recognize it and understand the danger it can pose to themselves and others. 


\section{REFERENCES}

Akers, Ronald. 2009. Social Learning and Social Structure. New York, NY: Routledge.

Baker, Peter. 2018. “'Use That Word!': Trump Embraces the 'Nationalist Label’” The New York Times, Oct. 23. Retrieved June 11, 2019 (https://www.nytimes.com/2018/10/23/us/politics/nationalistpresident-trump.html).

Baysinger, Timothy G. 2006. "Right-wing group characteristics and ideology." Naval Postgraduate School Monterey Ca Center for Homeland Defense and Security.

Bennett, David H. 1988. The Party of Fear: From Nativist Movements to the New Right in American History. Chapel Hill, NC: The University of North Carolina Press.

Berger, J. M. 2016. Nazis vs. ISIS on Twitter. A Comparative Study of White Nationalist and ISIS Online Social Media Networks. GW Program on Extremism.

Berlet, Chip, and Matthew N. Lyons. 2018. Right-wing populism in America: Too close for comfort. New York: Guilford Publications.

Blazak, Randy. 2009. “Toward a working definition of hate groups.” Hate Crimes, Volume 3: $133-162$

Bloch, Katrina Rebecca, Tiffany Taylor, and Karen Martinez. 2020. "Playing the Race Card: White Injury, White Victimhood and the Paradox of Colour-Blind Ideology in Anti-immigrant Discourse." Ethnic and Racial Studies 43(7): 1130-1148.

Bonilla-Silva, Eduardo. 2019. ““Racists,' 'Class Anxieties,' Hegemonic Racism, and Democracy in Trump's America." Social Currents 6(1): 14-31. 
Bossler, Adam and Thomas Holt. 2009. "On-line Activities, Guardianship, and Malware Infection: An Examination of Routine Activities Theory." International Journal of Cyber Criminology 3(1): 400-420.

Bossler, Adam M., Thomas J. Holt, and David C. May. 2012. "Predicting online harassment victimization among a juvenile population." Youth \& Society 44 (4): 500-523.

Bourhis, Richard Y. and Howard Giles. 1977. "The language of intergroup distinctiveness." Language, ethnicity and intergroup relations 13: 119.

Brands, Hal. 2017. "US grand strategy in an age of nationalism: fortress America and its alternatives." The Washington Quarterly, 40(1): 73-94.

Brown, Christopher. 2009. "WWW. HATE. COM: White supremacist discourse on the internet and the construction of whiteness ideology." The Howard Journal of Communications, 20(2): 189-208.

Bureau of Justice Statistics. 2017. Hate Crime Series. Washington, DC: U.S. Department of Justice. Retrieved May 28, 2020 (https://www.bjs.gov/index.cfm?ty=pbdetail\&iid=5967).

Gagnon, Andre, and Richard Y. Bourhis. 1996. "Discrimination in the minimal group paradigm: Social identity or self-interest?." Personality and Social Psychology Bulletin 22 (12): 1289-1301.

Carless, Will. 2018. “They Spewed Hate. Then They Punctuated it with the President's Name.” Reveal: From the Center for Investigative Reporting, April 19. Retrieved June 3, 2019 (https://www.revealnews.org/article/they-spewed-hate-then-they-punctuated-it-with-thepresidents-name/).

Chavez, Leo R. 2013. The Latino Threat: Constructing Immigrants, Citizens, and the Nation. Second Edition. Stanford, CA: Stanford University Press.

Choi, Kyung-shick. 2008. "Computer crime victimization and integrated theory: An empirical assessment." International Journal of Cyber Criminology 2 (1).

Citrin, Jack, and David O. Sears. 2009. "Balancing national and ethnic identities the psychology of e pluribus unum." Measuring identity: A guide for social scientists. 145. 
Citrin, Jack, and John Sides. 2008 "Immigration and the imagined community in Europe and the United States." Political Studies. 56(1): 33-56.

Citrin, Jack, and Matthew Wright. 2009. "Defining the circle of we: American identity and immigration policy." In The forum 7(3). De Gruyter.

Cohen, Lawrence E. and Marcus Felson. 1979. "Social Change and Crime Rate Trends: A Routine Activity Approach.” American Sociological Review 44: 588-608.

Colvin, Mark, Francis T. Cullen, and Thomas Vander Ven. 2002. "Coercion, social support, and crime: An emerging theoretical consensus." Criminology 40 (1): 19-42.

Costello, Matthew, Salvatore Restifo, and James Hawdon. 2019. “Anti-Immigrant Online Hate and the Rise of White Nationalism." Presented at the Annual Meeting of the Northcentral Sociological Association, March 29, Cincinnati, OH. Regular Session.

Costello, Matthew, James Hawdon, and Amanda Cross. 2017. "Virtually Standing Up or Standing By? Correlates of Enacting Social Control Online." International Journal of Criminology and Sociology 6:16-28.

Costello, Matthew, James Hawdon, and Thomas N. Ratliff. 2016b. "Confronting online extremism: The effect of self-help, collective efficacy, and guardianship on being a target for hate speech." Social Science Computer Review 35(5): 587-605.

Costello, Matthew, James Hawdon, Thomas Ratliff, and Tyler Grantham. 2016a. "Who Views Online Extremism? Individual Attributes Leading to Exposure.” Computers in Human Behavior 63: 311320.

Cowan, Gloria and Jon Mettrick. 2002. "The effects of target variables and setting on perceptions of hate speech1.” Journal of Applied Social Psychology, 32(2): 277-299.

Edgell, Penny, Douglass Hartmann, Evan Stewart, and Joseph Gerteis. 2016. “Atheists and Other Cultural Outsiders: Moral Boundaries and the Non-Religious in the United States.” Social Forces 95(2): 607-638. 
Ekins, Emily. 2017. "The Five Types of Trump Voters: Who They Are and What They Believe." A Research Report from the Democracy Fund Voter Study Group. Retrieved April 15, 2019 (file://C:/Users/admin/Downloads/FiveTypesOfTrumpVoters_2017june19.pdf.).

Eversley, Melanie. 2016. "Post-Election Spate of Hate Crimes Worse than Post-9/11, Experts Say.” USA Today, Nov. 12. Retrieved July 15, 2019 (https://www.usatoday.com/story/news/2016/11/12/post-election-spate-hate-crimes-worse-thanpost-911-experts-say/93681294/).

Fagan, Abigail A., and Paul Mazerolle. 2011. "Repeat offending and repeat victimization: Assessing similarities and differences in psychosocial risk factors." Crime \& Delinquency. 57: 732-55.

Federal Bureau of Investigation. 2018. “2017 Hate Crimes Statistics Released. Report Shows More Departments Reporting Hate Crimes Statistics.” FBI: News, Nov. 13. Retrieved April 24, 2019 (https://www.fbi.gov/news/stories/2017-hate-crime-statistics-released-111318).

Federal Bureau of Investigation: Uniform Crime Reports. 2017. “2016 Hate Crimes Statistics.” Retrieved February 26, 2019 (https://ucr.fbi.gov/hate-crime/2016/topic-pages/incidentsandoffenses).

Federal Bureau of Investigation. 2011. "Domestic Terrorism: Focus on Militia Extremism." Retrieved April 8, 2019 (https://www.fbi.gov/news/stories/2011/september/militia 092211).

Finkelhor, David, Richard K. Ormrod, and Heather A. Turner. 2007. "Re-victimization patterns in a national longitudinal sample of children and youth." Child abuse \& neglect, 31(5): 479-502.

Fleming, Michele J., Shane Greentree, Dayana Cocotti-Muller, Kristy A. Elias, and Sarah Morrison. 2006. "Safety in cyberspace: Adolescents' safety and exposure online." Youth \& Society 38 (2): 135-154.

Foxman, Abraham H. and Christopher Wolf. 2013. Viral hate: Containing its spread on the 
Internet. New York, NY: Macmillan.

Freilich, Joshua, Roberta Belli, and Steven Chermak, 2011, October. "United States Extremist Crime Database.” Retrieved March 1, 2019 (www.start.umd.edu/research-projects/united-statesextremist-crime-database-ecdb-1990-2010).

Fukuyama, Francis. 1992. The End of History. New York, NY: Free Press.

Gemignani, Marco and Yolanda Hernandez-Albujar. 2015. "Hate groups targeting unauthorized immigrants in the US: discourses, narratives and subjectivation practices on their websites." Ethnic and Racial Studies 38(15): 2754-2770.

Global Post. 2015. "White Americans Are the Biggest Terror Threat in The United States". Retrieved July 2, 2019 (https://www.mintpressnews.com/white-americans-are-the-biggest-terror-threat-in-theunited-states/211608/).

Golash-Boza, Tanya M. 2012. Immigration Nation: Raids, Detentions, and Deportations in Post-9/11 America. Boulder, CO: Paradigm.

Grant, Peter R. 1993. "Ethnocentrism in response to a threat to social identity." Journal of Social Behavior and Personality. 8(6): 143.

Grinberg, Emanuella. 2018. "4 Days, 5 Reports of Hate Crimes, and a Disturbing Trend Developing in America." CNN, Dec. 12. Retrieved Feb. 18, 2019 (https://www.cnn.com/2018/12/11/us/hatecrimes/index.html).

Hawdon, James. 2014. "Group Violence Revisited: Common Themes across Types of Group Violence.” In James Hawdon, John Ryan and Marc Lucht (Eds.) The Causes and Consequences of Group Violence: From Bullies to Terrorists: 241 - 254. Lanham, MD: Lexington Books.

Hawdon, James, Colin Bernatzky, and Matthew Costello. 2019. "Cyber-Routines, Political Attitudes, and Exposure to Violence-Advocating Online Extremism." Social Forces, 98(1): 329-354. 
Hawdon, James, Matthew Costello, Thomas Ratliff, Lori Hall, and Jessica Middleton. 2017b. "Conflict management styles and cybervictimization: Extending routine activity theory." Sociological Spectrum 37(4): 250-266.

Hawdon, James, Atte Oksanen, and Pekka Räsänen. 2017a. "Exposure to Online Hate in Four Nations: A Cross-National Consideration." Deviant Behavior 38(3): 254-266.

Hawdon, James, Atte Oksanen, and Pekka Räsänen. 2015. “Online Extremism and Online Hate: Exposure among Adolescents and Young Adults in Four Nations.” Nordicom-Information 37: 29-37.

Hawdon, James, Atte Oksanen and Pekka Räsänen. 2014. "Victims of Online Hate Groups: American Youth's Exposure to Online Hate Speech.” In James Hawdon, John Ryan and Marc Lucht (Eds.) The Causes and Consequences of Group Violence: From Bullies to Terrorists: 165- 182. Lanham, MD: Lexington Books.

Higham, John. 1988. Strangers in the Land: Patterns of American Nativism, 1860-1925. $2^{\text {nd }}$ ed. New Brunswick, NJ: Rutgers University Press.

Hirschfeld, Davis, Sheryl Gay Stolberg, and Thomas Kaplan. 2018. "Trump Alarms Lawmakers with Disparaging Words for Haiti and Africa.” The New York Times, Jan. 11. Retrieved June 15, 2019 (https://www.nytimes.com/2018/01/11/us/politics/trump-shithole-countries.html).

Huang, Jon, Samuel L. Jacoby, Michael Strickland, and K. K. Rebecca Lai. 2016. “Election 2016: Exit Polls.” The New York Times, Nov. 8. Retrieved June 22, 2019 (https://www.nytimes.com/interactive/2016/11/08/us/politics/election-exit-polls.html).

Hutchinson, Andrew. 2019. "Facebook Reaches 2.38 Billion Users, Beats Revenue Estimates in Latest Update." SocialMediaToday, April 24. Retrieved May 5, 2020 (https://www.socialmediatoday.com/news/facebook-reaches-238-billion-users-beats-revenueestimates-in-latest-upda/553403/). 
Illias, Shayerah, Katherine Fennelly, and Christopher M. Federico. 2008. “American Attitudes toward Guest Worker Policies.” International Migration Review 42(4): 741-766.

Johnson, Jenna. 2015. "Trump Calls for 'total and complete shutdown of Muslims entering the United States." Washington Post, Dec. 7. Retrieved April 11, 2019 (https://www.washingtonpost.com/news/post-politics/wp/2015/12/07/donald-trump-calls-fortotal-and-complete-shutdown-of-muslims-entering-the-united-states /?utm term = $.2233 \mathrm{ae} 5 \mathrm{c} 24 \mathrm{f} 5)$.

Jones, Jeffery M., 2019. “Mentions of Immigration as Top Problem Surpass Record High.” Gallup, July 23. Retrieved May 6, 2020. (https://news.gallup.com/poll/261500/mentions-immigration-topproblem-surpass-record-high.aspx).

Kaakinen, Markus, Atte Oksanen and Pekka Räsänen. 2018. "Did the Risk of Exposure to Online Hate Increase after the November 2015 Paris Attacks? A group Relations Approach.” Computers in Human Behavior, 78: 90-97.

Kaleem, Jaweed. 2019. "Latinos and transgender people see big increases in hate crime, FBI reports.” Los Angeles Times, Nov. 12, 2019. Retrieved Feb. 20, 2020 (https://www.latimes.com/worldnation/story/2019-11-12/hate-crimes-fbi-2018).

Keipi, Teo, Matti Näsi, Atte Oksanen, and Pekka Räsänen. 2017. Online Hate and Harmful Content: Cross-National Perspectives. London, UK: Routledge.

Leets, Laura. 2002. "Experiencing Hate Speech: Perceptions and Responses to Anti-Semitism and Antigay Speech.” Journal of social issues, 58(2): 341-361.

Leukfeldt, Eric Rutger and Majid Yar. 2016. “Applying Routine Activity Theory to Cybercrime: A Theoretical and Empirical Analysis." Deviant Behavior 37(3): 263-280. 
Lieberson, Stanley. 1980. A Piece of the Pie: Blacks and White Immigrants Since 1880. Berkeley, CA: University of California Press.

Lieven, Anatol. 2016. "Clinton and Trump: Two faces of American nationalism." Survival 58(5): 7-22. MacKinnon, David P., Jennifer L. Krull, and Chondra M. Lockwood. 2000. "Equivalence of the mediation, confounding and suppression effect." Prevention science 1 (4): 173-181.

Mammone, Andrea. 2019. "Rightwing Nationalists are on the Rise in Europe - and there's no Progressive Coalition to Stop Them.” The Washington Post, April 7. Retrieved June 4, 2019 (https://www.washingtonpost.com/outlook/2019/04/07/right-wing-nationalists-are-rise-europetheres-no-progressive-coalition-stop them/?noredirect=on\&utm term=.28f95aa4dc0e).

McClendon, McKee J. 2002. Multiple Regression and Causal Analysis. Long Grove, IL: Waveland Press. Mead, Walter Russell. 2013. Special providence: American foreign policy and how it changed the world. New Yorik, NY: Routledge.

Meddaugh, Priscilla Marie, and Jack Kay. 2009. "Hate speech or "reasonable racism?" the other in stormfront." Journal of Mass Media Ethics 24(4): 251-268.

Menand, Louis. 2018. "Francis Fukuyama Postpones The End of History. The New Yorker, Aug. 27. Retrieved June 8, 2019 (https://www.newyorker.com/magazine/2018/09/03/francis-fukuyamapostpones-the-end-of-history).

Milner, Murray, Jr. 2013. Freaks, Geeks, and Cool Kids: American Teenagers, Schools, and the Culture of Consumption. New York: Routledge.

Musumeci, Natalie. 2016. “KKK Celebrating Trump’s Election with Victory Parade.” New York Post, Nov. 11. Retrieved June 8, 2019 (https://nypost.com/2016/11/11/kkk-celebrating-trumps-electionwith-victory-parade/).

Näsi, Matti, Pekka Räsänen, Atte Oksanen, James Hawdon, Teo Keipi, and Emma Holkeri. 2014.

"Association between online harassment and exposure to harmful online content: A cross-national 
comparison between the United States and Finland." Computers in Human Behavior. 41: 137145.

Näsi, Matti, Pekka Räsänen, James Hawdon, Emma Holkeri, and Atte Oksanen. 2015. "Exposure to Online Hate Material and Social Trust among Finnish Youth.” Information, Technology and People 28(3): 607-622.

Newport, Frank. 2018. “Immigration Surges to Top of Most Important Problem List.” Gallup, July 18. Retrieved June 18, 2019 (https://news.gallup.com/poll/237389/immigration-surges-top-importantproblem \%20list.aspx?g source $=$ link newsv9\&g campaign $=$ item $244925 \& \mathrm{~g}$ medium $=$ copy

Ngai, Mae M. 2004. Impossible Subjects: Illegal Aliens and the Making of Modern America. Princeton, NJ: Princeton University Press.

Obinna, Denise N. 2018. "Ethnicity, Reception, and the Growth of American Immigration." Ethnic and Racial Studies 41(2): 171-188.

Okeowo, Alexis. 2016. "Hate on the Rise After Trump's Election.” The New Yorker, Nov. 16. Retrieved July 1, 2019 (https://www.newyorker.com/news/news-desk/hate-on-the-rise-after-trumpselection).

Phadke, Shruti, Jonathan Lloyd, James Hawdon, Mattia Samory, and Tanushree Mitra. 2018. "Framing Hate with Hate Frames: Designing the Codebook.” Pp 201-204 in Companion of the 2018 ACM Conference on Computer Supported Cooperative Work and Social Computing. Jersey City, NJ: ACM. doi 10.1145/3272973.3274055.

Pollin, Robert 2011. "Economic prospects: Can we please stop blaming immigrants?." In New Labor Forum. 20(1): 86-89. Sage CA: Los Angeles, CA: SAGE Publications.

Potok, Mark. 2017. The Trump Effect. Intelligence Report (Spring Issue). Retrieved Feb. 22, 2019 (https://www.splcenter.org/fighting-hate/intelligence-report/2017/trump-effect). 
Potok, Mark. 2015. The Year in Hate and Extremism. Intelligence Report (Spring Issue). Retrieved Feb. 22, 2019 (https://www.splcenter.org/fighting-hate/intelligence-report/2015/year-hate-andextremism-0).

Pratt, Travis C., and Francis T. Cullen. 2005. "Assessing macro-level predictors and theories of crime: A meta-analysis." Crime and justice 32: 373-450.

Pratt, Travis C., Kristy Holtfreter, and Michael D. Reisig. 2010. "Routine Online Activity and Internet Fraud Targeting: Extending the Generality of Routine Activity Theory.” Journal of Research in Crime and Delinquency 47(3): 267-296.

Rachman, Gideon. 2018. “Donald Trump Leads a Global Revival of Nationalism.” Financial Times, June 25. Retrieved July 24, 2019 (https://www.ft.com/content/59a37a38-7857-11e8-8e67$\underline{1 \mathrm{e} 1 \mathrm{a} 0846 \mathrm{c} 475)}$.

Räsänen, Pekka, Hawdon, James, Emma Holkeri, Matti Näsi, Teo Keipi, and Atte Oksanen. 2016. “Targets of Online Hate: Examining Determinants of Victimization among Young Finnish Facebook Users." Violence and Victims 31(4): 708.

Ratliff, Thomas N., James Hawdon, Jessica Middleton, Anna Tan, and David Snow. 2015.

“Domestic Extremism in the U.S. 1960-2015." Presented at the Annual Academy of Criminal Justice Sciences Meeting, March 4, Orlando, FL. Regular Session.

Restifo, Salvatore J., Vincent J. Roscigno, and Laura A. Phillips. 2019. "Racial/Ethnic Hierarchy and Urban Labor Market Inequality: Four Poignant Historical Cases.” City \& Community 18(2): 662688.

Reyns, Bradford. 2013. "Online Routines and Identity Theft Victimization Further Expanding Routine Activity Theory beyond Direct-Contact Offenses." Journal of Research in Crime and Delinquency. 50(2): 216-238.

Reyns, Bradford W. 2015. "A routine activity perspective on online victimisation." Journal of Financial Crime. 
Reyns, Bradford and Billy Henson. 2015. "The Thief with a Thousand Faces and the Victim with None Identifying Determinants for Online Identity Theft Victimization with Routine Activity Theory.” International journal of offender therapy and comparative criminology 60(10): 1119-1139.

Reyns, Bradford W., Melissa W. Burek, Billy Henson, and Bonnie S. Fisher. 2013. "The Unintended Consequences of Digital Technology: Exploring the Relationship between Sexting and Cybervictimization." Journal of Crime and Justice 36(1): 1-17.

Reyns, Bradford, Billy Henson, and Bonnie Fisher. 2016. "Guardians of the Cyber Galaxy: An Empirical and Theoretical Analysis of the Guardianship Concept from Routine Activity Theory as It Applies to Online Forms of Victimization." Journal of Contemporary Criminal Justice 32(2): $148-168$.

Reyns, Bradofrd W., Billy Henson, and Bonnie S. Fisher. 2011. "Being Pursued Online: Applying Cyberlifestyle-Routine Activities Theory to Cyberstalking Victimization.” Criminal justice and behavior 38(11): 1149-1169.

Rothschild, Zachary K., Mark J. Landau, Ludwin E. Molina, Nyla R. Branscombe, and Daniel Sullivan. 2013. "Displacing blame over the ingroup's harming of a disadvantaged group can fuel moral outrage at a third-party scapegoat." Journal of Experimental Social Psychology 49(5): 898-906.

Schain, Martin A. Shifting Tides: Radical-Right Populism and Immigration Policy in Europe and the United States. Washington, DC: Migration Policy Institute. Retrieved May 14, 2020 (https://www.migrationpolicy.org /research/radical-right-immigration-europe-united-states).

Schrag, Peter. 2010. Not Fit for Our Society: Immigration and Nativism in America. Berkeley, CA: University of California Press.

Southern Poverty Law Center. 2019. The Year in Hate and Extremisms: Rage Against Change. Intelligence Report: 166. Retrieved Jan 21, 2019 (https://www.splcenter.org/sites/default/files/intelligence_report_166.pdf). 
Stacey, Michele, Kristin Carbone-López, and Richard Rosenfeld. 2011. "Demographic change and ethnically motivated crime: The impact of immigration on anti-Hispanic hate crime in the United States." Journal of Contemporary Criminal Justice 27(3): 278-298.

Stack, Liam. Nov. 2016. “Globalism: A Far-Right Theory Conspiracy Buoyed by Trump.” The New York Times, Nov. 14. Retrieved April 18, 2019 (https://www.nytimes.com/2016/11/15/us/politics/globalism-right-trump.html).

The New America Foundation International Security Program. 2015. "Homegrown extremists.” Retrieved Jan. 4, 2019 (http://securitydata.newamerica.net/extremists/deadly-attacks.html.).

Timberlake, Jeffrey M. and Rhys H. Williams. 2012. "Stereotypes of U.S. Immigrants from Four Global Regions.” Social Science Quarterly 93(4): 867-890.

Trump, Donald J. 2016. “Transcript of Donald Trump's Immigration Speech.” The New York Times, Sept. 1. Retrieved April 5, 2019 (https://www.nytimes.com/2016/09/02/us/politics/transcript-trumpimmigration-speech.html.).

Tynes, Brendesha. 2006. "Children, adolescents and the culture of online hate." Handbook of children, culture and violence 25(6): 267-89.

Tynes, Brendesha, Lindsay Reynolds, and Patricia M. Greenfield. 2004. “Adolescence, race, and ethnicity on the Internet: A comparison of discourse in monitored vs. unmonitored chat rooms." Journal of Applied Developmental Psychology, 25(6): 667-684.

Tzelgov, Joseph, and Avishai Henik. 1991. "Suppression situations in psychological research: Definitions, implications, and applications." Psychological bulletin 109 (3): 524.

Vakhitova, Zarina I., Danielle M. Reynald, and Michael Townsley. 2016. "Toward the adaptation of routine activity and lifestyle exposure theories to account for cyber abuse victimization." Journal of Contemporary Criminal Justice 32 (2): 169-188. 
Wallace, Michael and Rodrigo Figueroa. 2012. "Determinants of Perceived Immigrant Job Threat in the American States." Sociological Perspectives 55 (4): 583-612.

Washington Post Staff. 2015. "Full Text: Donald Trump announces a presidential bid.” Washington Post, June 16. Retrieved June 5, 2019 (https://www.washingtonpost.com/news/postpolitics/wp/2015/06/16/full-text-donald-trump-announces-a-presidential$\underline{\mathrm{bid} / \text { ?utm term }=.8661 \mathrm{e} 121 \mathrm{c} 5 \mathrm{fl})}$.

Williamson, Vanessa, Theda Skocpol, and John Coggin. 2011. "The Tea Party and the Remaking of Republican Conservatism." Perspectives on Politics 9(1): 25-43. 